\title{
Hur aktiv är befolkningen - egentligen? Håller dagens rekommendationer?
}

\author{
Michael Sjöström, Agneta Yngve, Ulf Ekelund, Eric Poortvliet, \\ Anita Hurtig-Wennlöf, Andreas Nilsson, Maria Hagströmer, \\ Kamilla Nylund och Johan Faskunger
}

Enheten för preventiv näringslära (PrevNut), Institutionen för biovetenskaper vid Novum, Karolinska Institutet och Stockholms läns landsting, PrevNut vid Novum, SE-I4I 57 Huddinge, Sweden.

\section{Abstract}

Successful public health interventions demand a clear understanding of how, and to what extent, people are physically active. Physical activity is, however, difficult to measure accurately. We have tested various methods.

New insights into how, and to what extent, people are active were achieved. The data raised many issues regarding lifestyle physical activity. Is it the total time spent in moderate intensity that is important, or the achievement of continuous bouts? What is the implication for the current recommendations? There is obviously a need for a discussion about the current recommendations. A better understanding of the objective measurement of lifestyle physical activity is needed to clarify how, and to what extent, people are active.

Keywords: physical activity, health, disease prevention, assessment, accelerometer, doubly labeled water.

\section{Introduktion}

Dagens rekommendationer om hur mycket fysisk aktivitet som erfordras för att främja hälsa och förebygga sjukdom i befolkningen, baseras på en rekommendation som formulerades 1995 i USA (1). Att den relativa fysiska inaktiviteten var ett betydande och allt mer tilltagande folkhälsoproblem stod klart redan då. Det var viktigt för folkhälsans utveckling att de flesta människorna blev mer fysiskt aktiva. Det var därför angeläget att formulera en rekommendation, som var både riktig i sak, och som angav graden och arten av den aktivitet som erfordrades för en gynnsam allmän hälsoutveckling hos den enskilde individen. Den skulle också vara sådan att var och en kunde förstå och följa den.

Rekommendationen presenterades av en arbetsgrupp med representanter för Centers for Disease Control and Prevention (CDC) och American College for Sports Medicine (ACSM) (1), och har fâtt ett mycket starkt genomslag över hela världen. Förvisso var denna rekommendation inte ny då den kom, utan den hade efter hand tonat fram och redovisats $\mathrm{i}$ en serie brittiska och amerikanska dokument under åren dessförinnan (2). I Sverige, som var tidigt framme på detta område, presenterades redan pa 70- och 80-talen liknande rekommendationer (3).
Fysisk aktivitet definieras i det redovisade underlaget för rekommendationen, utifrån en definition som formulerades i mitten av 80-talet, som alla de kroppsrörelser vi utför med hjälp av vår muskulatur ("any bodily movement produced by skeletal muscles that results in energy expenditure") (4).

"Fysisk aktivitet" innefattar således all den aktivitet som vi utför till vardags, dvs under transporter, på arbete, i hemmet, samt på fritiden. Den sistnämnda domänen av vardagen inkluderar motion och idrott. Med motion avses sådan aktivitet som utförs planerat, strukturerat och repetitivt med syftet att förbättra eller bibehålla en god allmänkondition (1). Den övriga vardagliga aktiviteten utgör till sin omfattning en betydande, ofta helt övervägande, andel av den totala aktiviteten. På vilket sätt och $\mathrm{i}$ vilken omfattning denna aktivitet inverkar på hälsoutvecklingen hos den enskilde är mindre känt, men intresset bland forskare, folkhälsoarbetare och andra aktivitetsförespråkare inriktas nu allt mer mot denna andel av den totala aktiviteten.

Rekommendationen från 1995 lyder: "Every adult should accumulate 30 minutes or more of moderate-intensity physical activity on most, preferably all days of the week [...] intermittent bouts of physical activity, as short as 8 to 10 minutes, totaling 30 minutes or more on most days provide beneficial health and fitness effects". 
Underlaget för rådet om 30 minuters aktivitet, eller mer, på en ansträngningsnivå, som är något högre än den vardagliga ("moderate-intensity"), dvs en nivå motsvarande rask promenad, eller högre, utgörs av resultat från en del epidemiologiska studier, bland andra de sk Harward aluministudierna. Den bygger också på extrapoleringar av andra resultat och erfarenheter, samt på en del antaganden. Fokus har varit sambandet mellan fysisk aktivitet och hjärt-kärlsjukdom. Nytt var att man hävdade att hälsoeffekten av aktiviteten var lika god om den genomfördes i 3-4 omgångar på 8-10 minuter, som om den genomfördes i en samlad aktivitet om 30 minuter. Men det vetenskapliga underlaget för detta påstående är vid en närmare granskning förvånansvärt tunt.

Kunskapen om arten och graden av fysisk aktivitet i befolkningen är bristfällig. Det finns visst kunnande om den avsiktliga motionens omfattning och bestämningsfaktorer. Det finns däremot inte $\mathrm{i}$ något land data om den totala fysiska aktiviteten $\mathrm{i}$ befolkningen, hur den fördelas med avseende på kön, ålder och socioekonomiska förhållanden, etc. Aktivitetens karaktär, dvs. den intensitet den bedrivs på, och hur länge aktiviteten pågår (durationen), samt hur ofta aktiviteten i fråga återkommer (frekvensen) är obekant. Av detta följer att den ovan refererade allmänna rekommendationen inte är sakligt underbyggd i en omfattning som vore önskvärd.

Ett framgångsrikt folkhälsoarbete förutsätter bättre information än vad nu är fallet om den aktuella situationen, hur aktiva människorna egentligen är och på vilket sätt de är aktiva. Därmed kan problemen, exempelvis uttryckt i termer som den relativa inaktivitetens omfattning och karaktär, bättre identifieras. Hälsofrämjande och sjukdomsförebyggande politik kan tydligare formuleras, vettiga handlingsplaner kan upprättas och effektivare interventioner kan genomföras och utvärderas. Rimligheten i nu gällande rekommendation kan bättre bedömas. Diskussionen om sambandet mellan aktivitet och hälsa kan få bättre underlag. Fysisk aktivitet är emellertid svâr att mäta.

\section{Syfte}

Vi har prövat ett antal tillgängliga mätmetoder på olika befolkningsgrupper för att få en klarare bild av hur användbara dessa metoder är och också av hur aktiv befolkningen egentligen är. I denna presentation redovisas i korthet vilka dessa metoder är och vilka inledande slutsatser man kan dra utifrån de resultat som tagits fram.

\section{Subjektiva metoder}

Enkäter är vanligast förekommande i befolkningsstudier. De är billiga att ta fram och kan enkelt distribueras ut till ett stort antal individer. Tillför-litligheten i svaren är dock inte särskilt god. Då enkätfrågorna ofta är retrospektiva kan svårighet att minnas ge upphov till fel. Likaså kan oklart definierade termer, som exempelvis avser intensiteten $\mathrm{i}$ en aktivitet, ge upphov till missförstånd. Det finns en klar tendens att överskatta sin aktivitet (5). För många kan det vara svårt att hålla isär idealbilden, om hur fysiskt aktiv man bör vara, från den verkliga bilden.

En annan svårighet med enkäter har att göra med just det faktum att de är enkla att ta fram. Detta har inneburit att ett mycket stort antal formulär finns, som dessutom oftast använts bara någon enstaka gång. Frågorna är olika, och svaren är inte jämförbara, vilket gör att en samlad bild av aktivitetsläget inte kan fås. Ej heller kan tendenser skönjas. Visserligen torde det finnas fog för påståendet att aktiviteten har minskat de senaste decennierna. Vilken art och mer precis omfattning som denna minskning har är dock mindre bekant.

Mot bakgrund av detta har The International Physical Activity Questionnaire (IPAQ) nyligen utvecklats. Det är en uppsättning formulär (kort resp. långt, för självifyllande resp. intervju) som är utvecklat och testat gemensamt av en internationellt sammansatt grupp av forskare på området. Ett 25-tal centra från alla världsdelar har medverkat i det omfattande testarbetet. Frågorna i det långa formuläret är indelade i fyra kategorier som avser tid i fysisk aktivitet under totalt de senaste sju dagarna $i$ arbete, under transport, i hemmet och under fritid. Den sammanlagda tiden i aktivitet från de fyra kategorierna ger således ett mått på den totala omfattningen av fysisk aktivitet.

Frågorna om tid i aktivitet inom varje kategori är vidare indelade med avseende på intensiteten, vilket ger värdefull information om individens rörelsemönster. Dessutom täcker frågorna också tid i sittande (inaktivitet) under dagen.

Arbetet med att testa de olika versionerna har fallit väl ut. Formuläret har uppvisat en acceptabel reproducerbarhet och validitet (tillförlitlighet) ställt mot en objektiv metod. Därför överväger nu WHO att inkludera formuläret, eller anpassade versioner av det, i sitt globala program för övervakning av hälsoutvecklingen. Vi på PrevNut vid Novum har haft en central roll $i$ det bakomliggande utvecklingsarbetet och leder också det fortsatta arbetet med att utveckla och ytterligare förbättra 


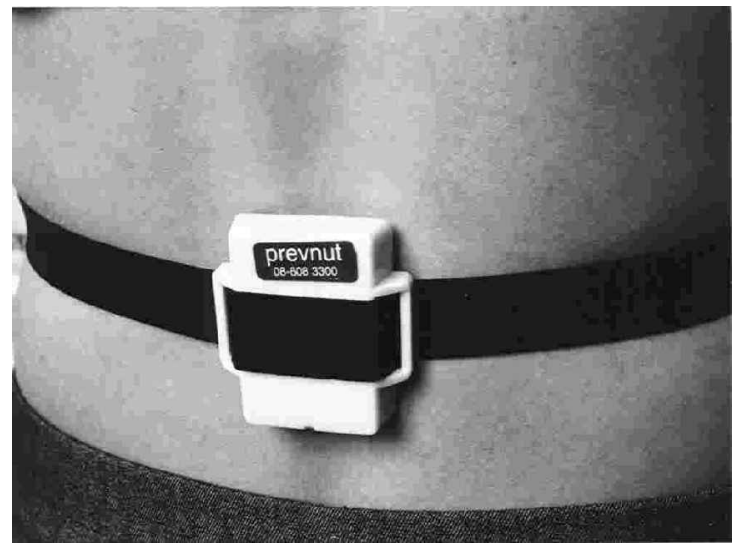

Fig. 1. Accelerometer (av märket CSA) fastspänd runt midjan pa en försöksperson.

formulären. Sammanställda resultat från kvalitetstestningen av IPAQ kan läsas på www.ipaq.ki.se, från vilken också formulären kan laddas ner.

\section{Objektiva metoder}

Behovet av en tillförlitlig objektiv metodik att använda vid bestämning av fysisk aktivitet på större urvalsgrupper är stort. Fördelen med en sådan är att flera av de kända felkällorna förenade med subjektiva metoder (enkäter) kan undvikas. Dessutom utgör en objektiv metod med god tillförlitlighet det enda acceptabla valet av referensmetod vid valideringar av subjektiva metoder. Dubbelmärkt vatten metodik (DLW), hjärtfrekvensregistrering och rörelsemätare (accelerometrar) är de mest använda metoderna. Vi har utförligt prövat dessa metoder mot varandra och tillämpat dem, och även jämfört dem med en subjektiv metod (aktivitetsdagbok) (7-12).

DLW metoden kan bestämma den totala energiförbrukningen över tid med mycket bra precision, men är samtidigt allt för dyr för att användas i större studier. Dess oförmåga att bestämma aktivitetsmönster är även en anledning till behov av andra objektiva metoder. Hjärtfrekvensregistrering och rörelsemätning med accelerometer kan båda användas för att bestämma sâväl aktivitetens intensitet och duration som dess frekvens. Fördelen med accelerometer är att den är behändig att handskas med. Instrumentet, en liten plastdosa som bärs runt midjan, registrerar kroppsrörelser minut för minut under flera dagar eller veckor (Figur 1). Dess mätvärde (counts) återger därmed en mer direkt mätning av den fysiska aktiviteten, vilket är en

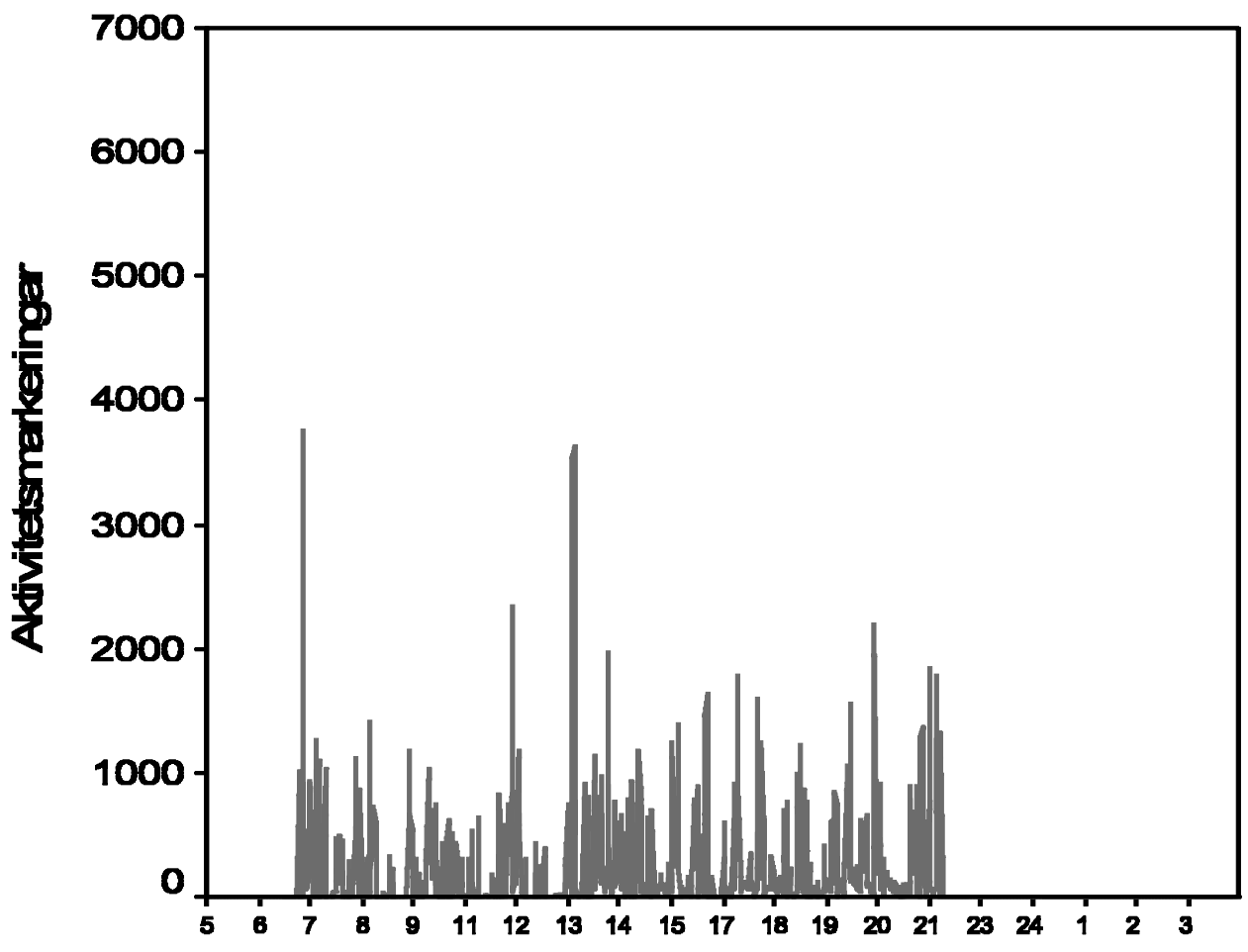

Tid på dygnet

Fig. 2. Registrering av en persons fysiska aktivitet mätt med accelerometer (CSA) minut för minut under ett helt dygn. Aktiviteten uttrycks i markeringar (sk counts). Cirka 2000 markeringar motsvarar măttlig intensitet. 
styrka jämfört med den indirekta mätningen av aktivitet som sker vid hjärtfrekvensregistrering. De flesta tillgängliga accelerometrar registrerar de rörelser som sker vertikalt (uniaxial mätare). Figur 2 visar exempel på en registrering över en dag av vaken tid.

Vi har genomfört utvärderingar av en sådan rörelsemätare, en uniaxial accelerometer (av märket CSA), den idag mest använda, dels vad gäller test av dess validitet mot DLW metodik (9), och dels dess förmåga till noggrann analys av intensitetsmönster (10). Den har i båda avseendena visat goda resultat. En svaghet är svårigheten att korrekt kunna spegla ökningen i energiförbrukning som sker vid cykling, gång i trappor eller stillastående aktiviteter, etc. Den kan heller inte användas i vatten. Instrumentet är trots dessa felkällor att anse som ett lämpligt verktyg för att spegla hela det vakna dygnets fysiska aktivitet. Metoden och utrustningen (CSA) har också fått ett genomslag globalt och är flitigt använd i fältstudier för bestämning av mängd och mönster av fysisk aktivitet.

\section{Utfall}

Hur aktiv är då befolkningen egentligen? Håller dagens rekommendation, dvs är rekommendationen om minst 30 minuters aktivitet dagligen rimlig? En betydande andel av befolkningen tycks, för att mycket kort sammanfatta framtagna data, vara aktiv i 30 minuter per dag totalt, men få om ens några uppfyller kravet på kontinuerlig aktivitet om minst $3 \times 10$ minuter som rekommendationen föreskriver, särskilt om aktiviteten ska vara i den avsiktliga motionens form.

Är det den totala aktiviteten på en något förhöjd nivå, som är viktig, eller måste kravet på kontinuerliga episoder uppfyllas? Här behövs fler och bättre erfarenheter frân mätning av aktivitet komma till, liksom mer forskning om sambanden mellan aktivitet och hälsa. Mycket behöver här uppenbarligen diskuteras och rekommendationen eller andra inarbetade synsätt kanske omprövas. Basen för dessa diskussioner är data, som på ett tillförlitligt sätt beskriver aktivitetens karaktär och omfattning i befolkningen.
Vi avser återkomma med mer utförlig redovisning i senare nummer av Scand J Nutrition.

\section{References}

1. Pate R, Pratt M, Blair S et al: Physical activity and public health: A recommendation from the Centers of Disease Control and Prevention and the American College of Sports and Medicine. JAMA 1995;273:402-7.

2. Killoran AJ, Fentem P, Caspersen C: Moving on. International perspectives on promoting physical activity. Health Education Authority 1994.

3. Kost, Motion \& Hälsa. Socialstyrelsen och Statens livsmedelsverk, Liber/Allmänna förlaget, Stockholm, 1986.

4. Caspersen C, Powell K, Christenson G: Physical activity, exercise and physical fitness: Definitions and distinctions for health-related research. Public Health Rep 1985; 100:126-31.

5. Duncan GE, Sydeman S, Perri MG, Limacher M, Martin $\mathrm{AD}$ : Can sedentary adults accurately recall the intensity of their physical activity? Prev Med 2001;33:18-26.

6. Ekelund U, Yngve A, Sjöström M: Total daily energy expenditure and patterns of physical activity assessed by two different methods in adolescents. Scand J Med Sci Sports 1999;9:257-64.

7. Ekelund U, Yngve A, Sjöström M, Westerterp K: Field evaluation of the Computer Science and Application's Inc. activity monitor during running and skating training in adolescent athletes. Int J Sports Med 2000;21:586-92.

8. Ekelund U, Sjöström M, Yngve A, Westerterp K: Total daily energy expenditure and pattern of physical activity measured by minute-by-minute heart rate monitoring in 14-15 year old Swedish adolescents. Eur J Clin Nutr 2000;54:195-202.

9. Ekelund U, Sjöström M, Yngve A et al: Physical activity assessed by activity monitor and doubly labeled water. Med Sci Sports Exerc 2001;33:275-81.

10. Nilsson A, Ekelund U, Yngve A, Sjöström M: Assessing physical activity among children with accelerometers using different time sampling intervals and placements. Pediatr Exerc Sci 2002;14:75-84.

11. Ekelund U, Yngve A, Westerterp K, Sjöström M: Energy expenditure assessed by heart rate and doubly labeled water in young athletes. Med Sci Sports Exerc 2002;34(8): (in press).

12. Ekelund U: Assessment of physical activity and energy expenditure in adolescents. Akademisk avhandling, Karolinska Institutet, Stockholm, 2002.

\section{Michael Sjöström}

PrevNut vid Novum, SE-|4| 57 Huddinge, Sweden.

E-mail: michael.sjostrom@prevnut.ki.se 